Progress in Physical Geography 25,1 (2001) pp. 1-21

\title{
The species-area relationship: new challenges for an old pattern
}

\author{
Mark V. Lomolino
}

Oklahoma Biological Survey, Oklahoma Natural Heritage Inventory and Department of Zoology, University of Oklahoma, Norman, OK 73019, USA

\begin{abstract}
The species-area relationship (i.e., the relationship between area and the number of species found in that area) is one of longest and most frequently studied patterns in nature. Yet there remain some important and interesting questions on the nature of this relationship, its causality, quantification and application for both ecologists and conservation biologists.

Traditionally, the species-area relationship describes the very general tendency for species number to increase with island area; a relationship whose slope declines (but remains positive) as area increases. The true relationship, however, may be much more complicated than this, and may in many cases approximate a sigmoidal relationship. On small islands, species number may vary independently of island area. Species richness then increases as we consider larger islands, but the curve eventually slows and asymptotes or levels off when richness equals that of the the source or mainland pool. The relationship may also include a secondary phase of increase in richness if island area becomes large enough to allow in situ speciation.

Causal explanations for this relationship may, therefore, need to be multifactorial and include a range of processes from disturbance and stochastic variation in habitat quality on the very small islands, to ecological interactions, immigration, extinction and, finally, evolution on the larger islands.
\end{abstract}

Key words: area, biogeography, diversity, islands, species-area, species richness.

\section{Introduction}

It is common, perhaps axiomatic, to refer to the species-area relationship as one of ecology's few laws (Schoener, 1976). According to a very broad consensus of ecologists, the pattern has two principal features: 1) species richness of a given taxon increases with the area sampled, and 2) the rate of increase slows for the larger islands or patches of habitat (Figure 1).

Because species richness is such a fundamental property of biotic communities, the theoretical basis and practical applications of the species-area relationship have remained active and important foci of ecology throughout its history. Moreover, the 


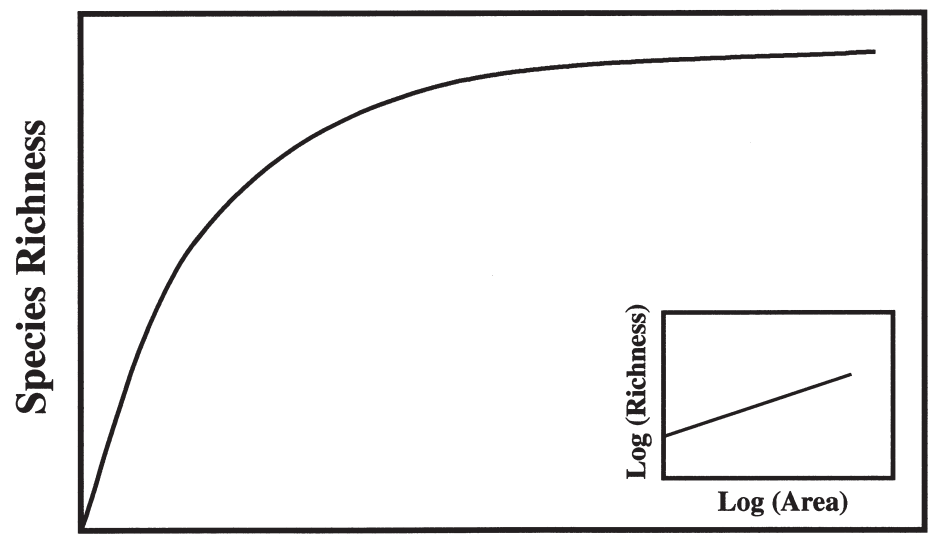

Island Area

Figure 1 General form for the species-area relationship illustrating its two principal features: species richness increases with increasing island area, but the rate of increase slows for the larger islands. This relationship is plotted in arithmetic (un-transformed space), but can be linearized using log-transformations to facilitate statistical analyses or to assist visualization of the relationship over a broad range in island area (see inset)

species-area relationship serves as a useful tool for exploring other patterns of biological diversity. For example, Rosenzweig's (1995) explanation of latitudinal gradients in species diversity, a pattern that rivals the species-area relationship in generality, is largely based on latitudinal gradients in areas of the world's life zones. In a similar vein, elevational gradients in species richness may be causally related to the species-area relationship: montane communities occupy less area than those of the lowlands (see discussions in Heaney, 2000; Lomolino, 2000a; 2001). MacArthur and Wilson's equilibrium theory of island biogeography, which has reigned as paradigm of the field for over three decades, was derived as a natural extension of the species-area relationship. As MacArthur and Wilson (1967: 8) wrote in their seminal monograph, 'Theories, like islands, are often reached by stepping stones. The species-area curves are such stepping stones.'

The species-area relationship also serves as an invaluable tool for studying the effects of other environmental variables. Given the very general and often dominant effects of area on biological diversity, ecologists must often use statistical models to remove the effects of area before evaluating the influence of other variables (Figure 2). The species-area relationship has also played an important role in explaining past and predicting future changes in biological diversity. While a number of mass extinctions of the geological record have been attributed to celestial events, others may well have been associated with climatic and tectonically driven changes in the earth's principal ecosystems (Figure 3). In more recent times, with the threat of anthropogenic changes in the native landscapes, ecologists and conservation biologists often apply models of the species-area relationship to predict losses in biological diversity (Harris, 1984; Shafer, 1990; Brooks et al., 1997; 1999b). 


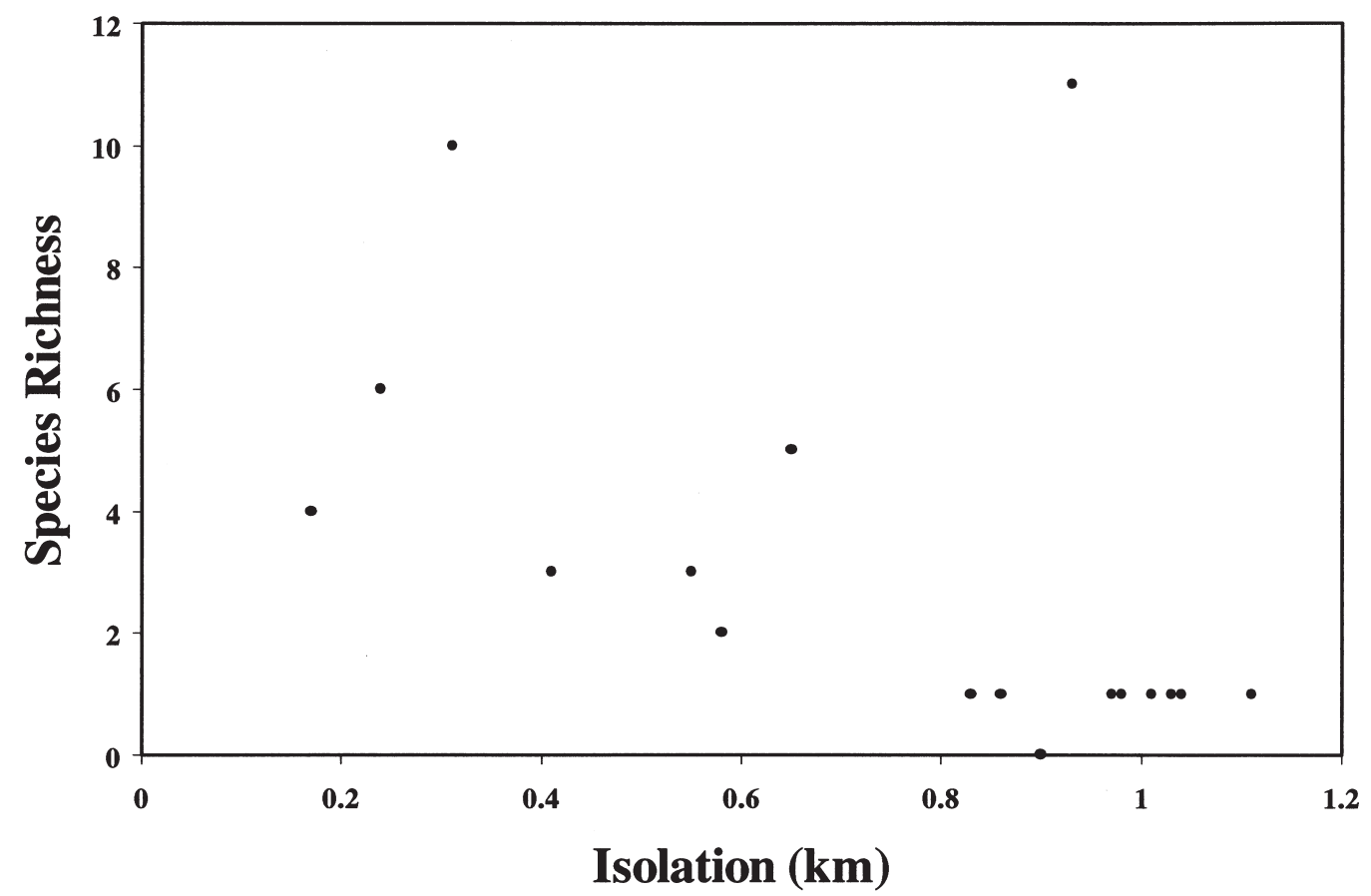

Figure 2 The species-area relationship may be used as an analytical tool to explore the association between species richness and other environmental variables (such as island isolation or elevation). Here, the species-isolation relationship for nonvolant mammals of the Thousand Island Region (St Lawrence River, N. America) is difficult to detect unless the effects of island area are first removed (e.g., using partial correlation methods and graphing residuals of the species-area relationship against island isolation; see Lomolino, 1982)

Given its fundamental importance to both theoretical and applied ecologists, a summary and reassessment of the science of the species-area relationship are in order. Despite the long and distinguished history of this body of research, challenges to the generality, causal basis and the very nature of this pattern are noteworthy and, at least in recent years, have been gaining momentum. Therefore, my purpose here is to summarize both the more traditional and unconventional, but perhaps revolutionary, views of what is truly one of nature's most fundamental patterns.

\section{Historical development}

The species-area relationship is not just reported to be one of ecologist's most general patterns, but is one of the oldest. In fact, descriptions of this relationship predate the field of ecology, perhaps by centuries. Watson (1859) has been credited with the earliest 'discovery' of the pattern, or at least the first plot of a species-area relationship (Rosenzweig, 1995: 8-9, after Dony, 1963). Although there remains some question as to 


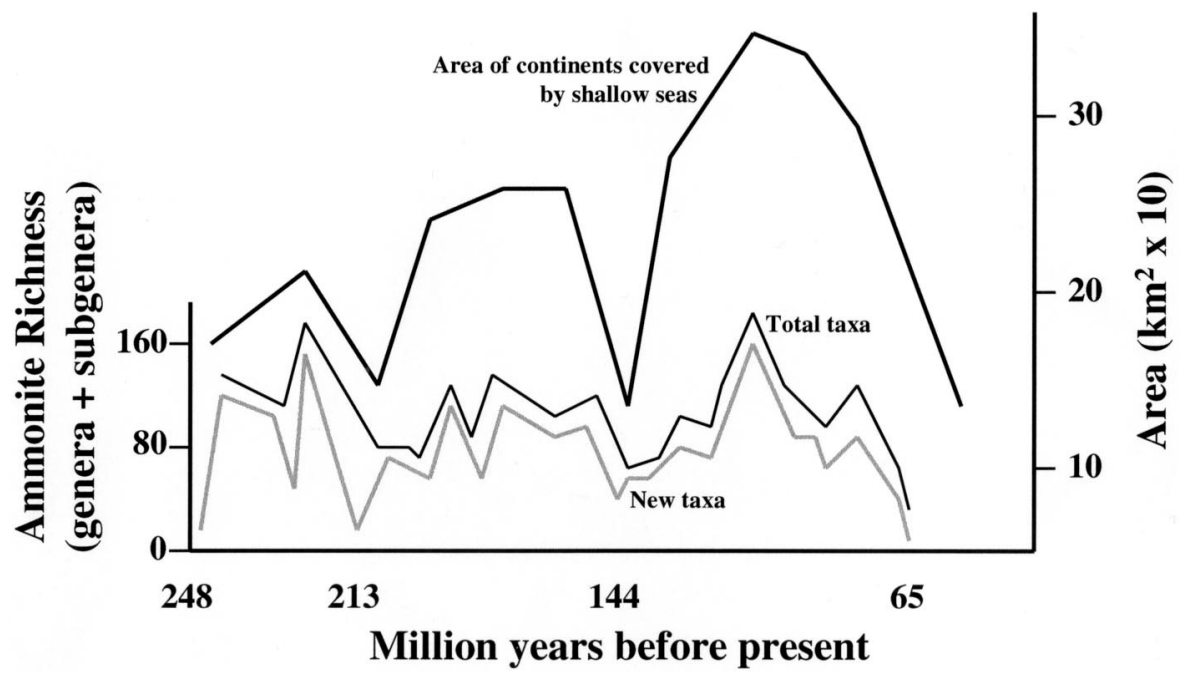

Figure 3 The diversity, evolution and extinction of shallow water marine organisms appears to be closely associated with the area of their habitat

Source: Brown and Lomolino, 1998, after Hallam, 1983

whether Watson actually plotted the relationship (or just presented a very extensive series of tables describing the relationship between British plant diversity and area sampled), it is clear that the pattern was well known to naturalists of the eighteenth and nineteenth centuries. In 1778, Johann Reinhold Forster published an account of observations he made during a circumnavigation of the globe with Captain James Cook. Among many other insights regarding the relationships between diversity, climate and geography, Forster observed that the number of plants found on islands increases with island area (resources and diversity habitats). Later, in the early 1800s, Augustin de Candolle (1820) confirmed Forster's observations of species-area relationships for insular floras and added that, while area has a dominant effect, isolation, island age, climate and volcanism also influence the diversity of insular plant communities (see discussion in Brown and Lomolino, 1998: 13-20). In 1859 Watson observed that very small sample areas, equivalent to only a fraction of the total area of Great Britain, contained nearly half all of its species. After examining the diversity and area of numerous sites throughout the world, Alfred Russell Wallace concluded that, not only were species and area related for most types of organisms and ecosystems, but the rate of increase in richness was higher in the smaller areas (Wallace, 1910, cited in Williams, 1964). Thus, in the nineteenth century, biogeographers understood and described both features of the species-area relationship.

Yet, we can speculate that the principal features of this relationship were known to early humans well before we started calling ourselves ecologists or biogeographers. All but the most primitive societies of hunters and gatherers must have understood that the variety of food plants, wildlife and fish they encountered increased with both the amount of time invested and with the total area covered. It is just as likely that these early humans understood that their likelihood of encountering new items decreased as 
the time and area they covered increased. This, of course, is the second feature of the species-area relationship, an ecological version of the law of diminishing returns. It is also an expression of a very general principle of physics: the diversity of any physical entities (from atomic particles, to organisms, to entire planets and stars) increases, but at an attenuating rate, with the amount, or volume, of space considered. Therefore, rather than marvel over the generality of this 'ecological' pattern, perhaps we should question why it took centuries to advance the science of this relationship beyond the relatively simple understanding of its principal features.

It was not until the 1920s that Arrhenius (1921) and Gleason (1922) expressed this relationship in mathematical terms. This was indeed a critical, albeit long-awaited, advance in the study of this pattern, primarily because it enabled scientifically rigorous investigations of species-area curves. Only then could biogeographers and ecologists use comparative methods to search for and evaluate causal explanations, or apply species-area models to make predictions and develop strategies for conserving biological diversity. It still, however, would take another four decades before the generality of this pattern was well established in quantitative terms by Frank Preston, an engineer and a naturalist (1962).

\section{Quantifying the relationship}

As noted above, this important advance in the science of the species-area relationship came long after it was first understood and described by early naturalists. Although there are many alternative, mathematical formula that may be used to quantify the species-area relationship, nearly all ecologists and biogeographers utilize the models developed by Arrhenius (1921) and Gleason (1922) in the 1920s (but see Flather, 1996, for a comparison among nine alternative mathematical models). Both these models share two essential features: they describe functions whose slopes are positive, but decline (slopes become less steep) with increasing area. Expressed in mathematical terms, an ideal species-area model should include two parameters, each describing a different, principal feature of this relationship: one a measure of the initial trajectory of the curve, and the other a measure of the rate of change in that trajectory (or slope), with increasing area.

The formula for Arrhenius' 'power model' is simple:

$$
S=c(\text { Area })^{z}
$$

where $c=$ the 'initial trajectory' and $z=$ a measure of the rate of change in the slope with increasing area. The slope is linear for $z=1$, increasing if $z>1$, decreasing if $z<1$.

The formula for Gleason's 'semi-log' model is equally simple:

$$
S=k_{1}+k_{2} \log \text { (Area) }
$$

where $k_{1}=$ the intercept of the curve in arithmetic space (the power model lacks a nonzero intercept in arithmetic space); $\log$ (Area) is a logarithmic transformation which ensures the slope of the curve declines with increasing area; and $k_{2}=$ a direct measure of the initial and overall slope (given the particular log-base used).

The power model includes two variables $(c$ and $z$ ) that describe the two fundamental 
features of the species-area relationship. On the other hand, because the semi-log model has a real intercept (i.e., in arithmetic space), it may seem to have some advantage over the power model. After all, all species require some minimal area to maintain their insular populations. Therefore richness should not rise above zero before this critical minimum area is exceeded (thus, the intercept of the semi-log model, $k_{1}$, should be negative). Yet, over a broad range of area, this apparent advantage may seem to be just a nuance that can be overlooked. Both models seem to perform well in explaining the species-area relationship. The semi-log model tends to be used more frequently by phytogeographers, but the power model has become the most commonly used model for biogeographers, in general.

Parameters of both models are readily estimated using regression analyses. For the power model, both area and species richness are log-transformed and then the following regression model is used to estimate $z$ and $c$ (actually, $\log [c]$ ):

$$
\log (\text { Species })=\log (c)+z[\log (\text { Area })]
$$

Thus, $\log [c]$ and $z$ are estimated as the intercept and slope in log-log space, respectively.

For the semi-log model, area is log-transformed and the regression model is

$$
\text { Species }=k_{1}+k_{2}[\log (\text { Area })]
$$

Here, $k_{1}$ and $k_{2}$ are estimated as the intercept and slope, respectively, in semi-log space.

It is important to emphasize that $z$ and $k_{2}$ are not the slopes for the true species-area relationship (i.e., in arithmetic space). In the power model, the species-area slope is influenced by both $c$ and $z$, while the slope estimated by the semi-log model is a function of both $k_{2}$ and the logarithmic transformation. In addition to estimating model parameters $\left(c, z, k_{1}\right.$ and $\left.k_{2}\right)$, regression analysis also provides estimates of their standard errors, thus enabling searches for central tendencies in these parameters and statistical comparisons of differences in these values among species groups (e.g., comparisons in $z$-values among taxonomic or functionally defined groups of species) or among types of archipelagos (e.g., isolated versus nearshore, or tropical versus temperate; see Schoener, 1976; Connor and McCoy, 1979; Martin, 1981; Wright, 1981; Lomolino, 1984).

Comparisons of the statistical efficacy or explanatory ability of these two models (largely based on $r^{2}$ values) appear equivocal (Flather, 1996; Scheiner et al., 2000). It should be noted that these estimates of $r^{2}$ values may not be directly comparable because they are based on different bivariate transformations (regressions run in log-log space versus those in semi-log space for the power and semi-log models, respectively). Such estimates are not true measures of the proportion of variation in species richness that is explained by variation in island area because one or both of these variables are transformed before running the regressions. To make such estimates of $r^{2}$ values for species-area relationships, it may be necessary to use nonlinear regression procedures (where species richness and island area, untransformed, are dependent and independent variables, respectively).

All this aside, quantitatively rigorous studies of the species-area relationship have largely become an exercise of applying just one model - the log-log based power model, and analysing trends in just one of its parameters $-z$. In fact, $z$ has been elevated to the level of a 'canonical' value (Preston, 1962), one that seems to be viewed as a Rosetta 
stone for ecologists studying a broad range of patterns, from species-area relationships on islands, to latitudunal and elevational gradients in diversity and the loss of biological diversity due to fragmentation (Rosenzweig, 1995; Blackburn and Gaston, 1997; Brooks et al., 1997; Willig and Lyons, 2000). z can be viewed as a scaling factor, rather than just the 'slope' of the species-area relationship. When $z$ equals 1.0, the slope of the species-area relationship is scale invariant; i.e., the slope is constant (equal to c) and it is linear regardless of the range in area considered. We know, however, that in nearly all cases, the slope of the species-area relationship is scale variant and, because $z<1.0$, the slope decreases with increasing area.

Interest in $z$-values is, in many cases, well justified and has generated some important insights into the assembly of natural communities (e.g., Rosenzweig, 1995). Yet many quantitative analyses of the species-area relationship focus solely on this one parameter $-z$, sometimes misinterpreting its meaning, extrapolating beyond its relevance, and ignoring the relevance of $c$. Empirical estimates of $z$-values are often used to test predictions concerning the 'slope of the species-area relationship.' Such exercises are only valid if $c$-values are invariant among archipelagos or taxa. Yet we know from some extensive reviews of the species-area relationship (e.g., Connor and McCoy, 1979; McGuiness, 1984) that this is far from the case. $z$ is relatively conservative (typically ranging from 0.1 to 0.4 ) while $c$ typically varies by three to five orders of magnitude among insular biotas (put otherwise, $z$ and $\log _{10}(c)$ vary by equivalent factors, i.e., three to five times). The potential pitfalls of viewing $z$ (alone) as the slope of the species-area relationship go beyond any semantic distinctions. Although $c$ and $z$ describe different features of the species-area relationship (i.e., the initial slope and the scale dependence, or rate of change in that slope, respectively), they both combine to determine the slope. Given this, it seems especially surprising that few scientists have explored the central tendencies and biologically relevant variation in $c$-values. An exceptional case study is one conducted by Stephen Jay Gould just over two decades ago. Gould (1979) argued that the biological meaning of $c$ was unappreciated, largely because this parameter was regarded as intractable. As an illustration, Gould (1979) cited Haas (1975: 372) who apparently typified the views of his contemporaries (and most modern biogeographers as well): 'It is affected variously by the density of the organisms, the number of species in the taxa, degree of isolation, and the scale with which the area is measured. In fact, so much variation is sopped up by $c$ that particular values of it are hardly ever discussed.' Despite this, Gould (1979) offered a relatively simple, but potentially instructive means to investigate the biological relevance of $c$ (see Table 1 from his article).

Some recent studies by Michael Willig and Kathleen Lyons (2000) provide some tantalizing glimpses of an emerging and potentially insightful body of research which explores geographic variation in both $z$ and $c$. They compared cumulative species-area curves for mammals sampled across nested (i.e., inclusive) plots within latitudinal bands of North and South America. The pattern emerging from these studies is that along a gradient from the equator to the poles, $z$-values increase while $c$-values decrease. In addition to revealing an interesting geographic gradient in $c$-values, these and other studies also suggest a potentially important, yet unappreciated, pattern of covariation or interdependence of $c$ and $z$. Given the well established pattern of latitudinal gradients in richness, the asymptote of the species-area relationship $\left(S_{\text {pool }}=\right.$ $S_{\text {max }}$ ) decreases as we move polewards. Therefore, a poleward increase in $z$-values 
(corresponding to more linear species-area curves in regions with lower $S_{\text {pool }}$ ) must be accompanied by reduced $c$-values (Figure 4a). Perhaps not surprising, MacArthur (1965; 1969; 1972) made some early predictions along the same lines: namely, that $z$ and/or $c$ should vary with latitude (see also Connor and McCoy, 1979: 809-11).

Patterns of covariation or interdependence of $c$ and $z$ may be expected in other applications. Preston (1962) anticipated this pattern of covariation in his seminal article on the species-area relationship. In comparison to samples of mainland biotas, species-area relationships for biotas of isolated islands tend to be more linear (higher $z$ value), but have fewer species per unit area (and, therefore, lower $c$-values than mainland curves). This pattern of covariation of $c$ and $z$ has re-emerged in Rosenzweig's (1995) recent theory of species diversity in space and time (Figure 4b). Because species-area relationships of archipelagos within the same biotic region share a common species pool, their curves must converge on the same point (i.e., the area

required to reach $S_{\text {pool }}$. Therefore, an increase in $z$-values between archipelagos must again be accompanied by a compensatory decrease in $c$-values.

\section{Reassessing the fundamental pattern: the sigmoidal curve}

Some recent developments in biogeography have raised some serious questions, not just on the best model for the species-area relationship, but on the fundamental nature of this relationship. Depending on the scale, or range in island area considered, the species-area relationship may include two features that have been largely overlooked, at least in terms of our attempts to quantify the relationship.

These additional features were appreciated by at least some biogeographers for many decades. As implied above, species richness is a bounded relationship - it cannot exceed the richness of the species pool (unless in situ speciation occurs; see below). While this is entirely obvious, neither the power or semi-log models include this constraint richness never levels off. Similarly, neither model includes an additional feature of the species-area relationship that was reported over four decades ago - the small island effect. As MacArthur and Wilson (1967) observed in their seminal monograph, species richness may be uncorrelated with island area for relatively small islands (see also Wiens, 1962; Niering, 1963; Whitehead and Jones, 1969; Woodruffe, 1985; and Loehle, 1988; Lomolino, 2000b).

Therefore, if we sample islands across an appreciable range in island area, including numerous small islands, the species-area relationship may take the form of a sigmoidal curve (Figure 5). Just as there is need for systematic and statistically rigorous studies of biologically relevant variation in $c$-values (see above discussion), we also need to evaluate the generality of the small island effect. Perhaps the small island effect may prove to be a trivial wrinkle in the more general, canonical form of the species-area relationship. Yet we should not arrive at this conclusion without conducting the appropriate studies.

Two methodological points are relevant here. First, we tend to oversample large islands. That is, frequency distributions of both true and habitat islands tend to be rightskewed and highly leptokurtic (Figure 6), while the subset of islands we sample tend to be biased towards the larger islands. Perhaps this is justified because of the relatively high richness found on the very large islands. On the other hand, patterns and 


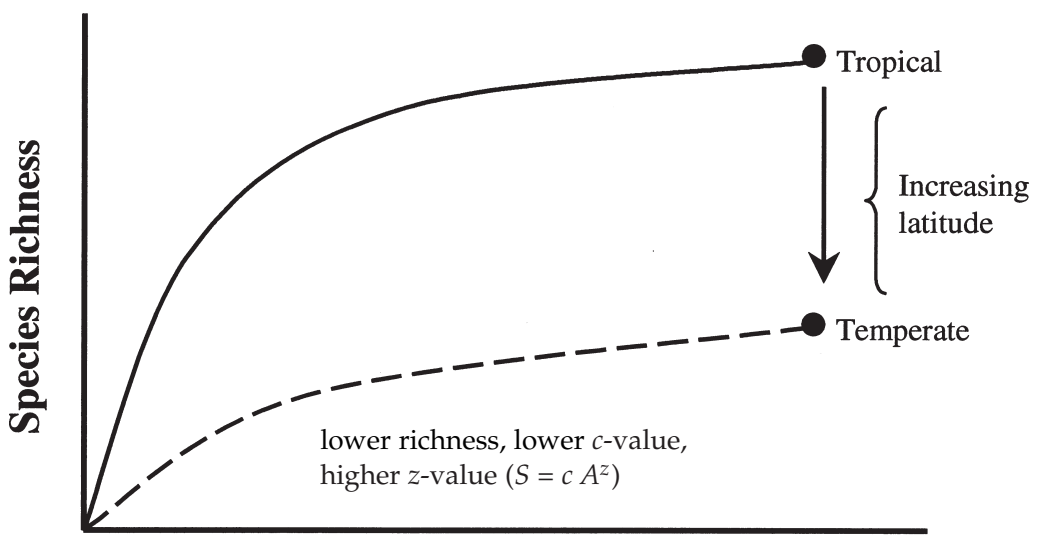

(a)

\section{Island Area}

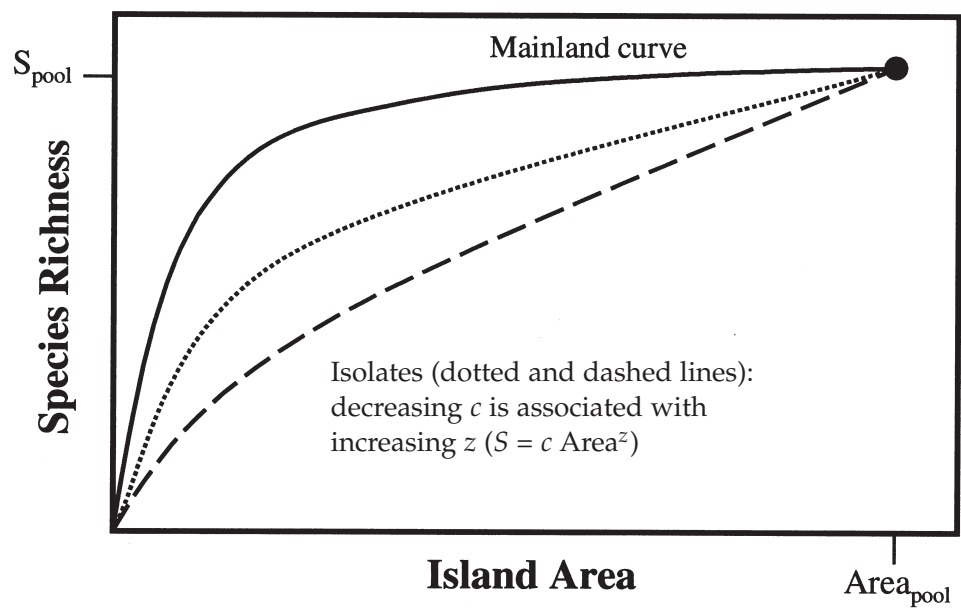

(b)

Figure 4 In the power model for the species-area relationship $(S=c$ Area $\left.^{z}\right)$, the slope of the relationship is influenced by both regression parameters, and it appears that $c$ and $z$ (measures of the initial slope, and the rate of change in the species-area slope, respectively) may covary for related families of curves. (a) For example, because species richness tends to decrease with increasing latititude, the increase in $z$ values (i.e., more linear species-area relationship) reported by Willig and Lyons (2000) for higher latitudes must be accompanied by a corresponding decrease in c-values; (b) because species-area curves of archipelagos or habitat islands within the same region are derived from the same species-pool, they will converge at the co-ordinates corresponding to the area and richness of that pool (see Rosenzweig, 1995). Thus, curves with higher $c$-values must also have lower $z$-values 


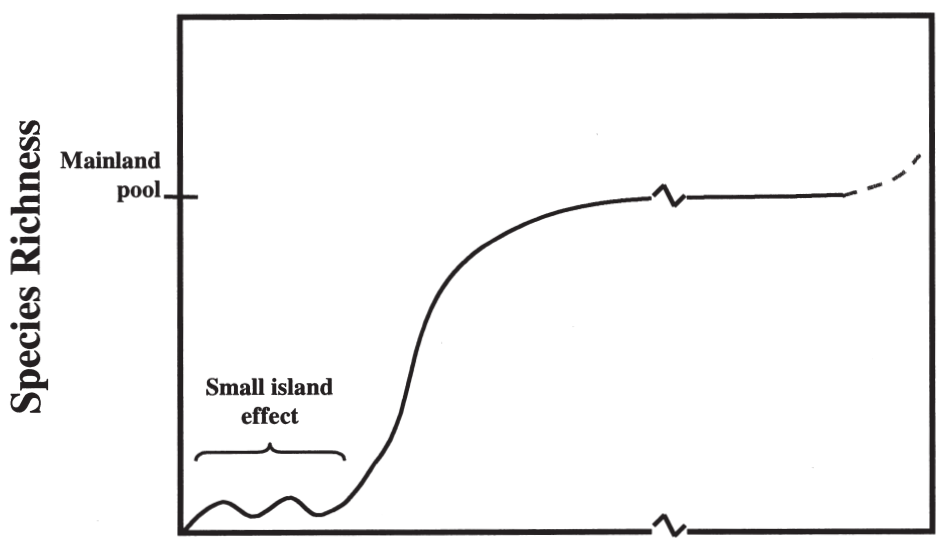

Island area

Figure 5 The possible, sigmoidal form of the species relationship includes potential, small island effects (the tendency for richness to vary independent of area on the smaller islands), along with the principal features of the relationship illustrated in Figure 1. The dashed line indicates a secondary phase of increase in species richness corresponding to islands large enough to allow in situ speciation

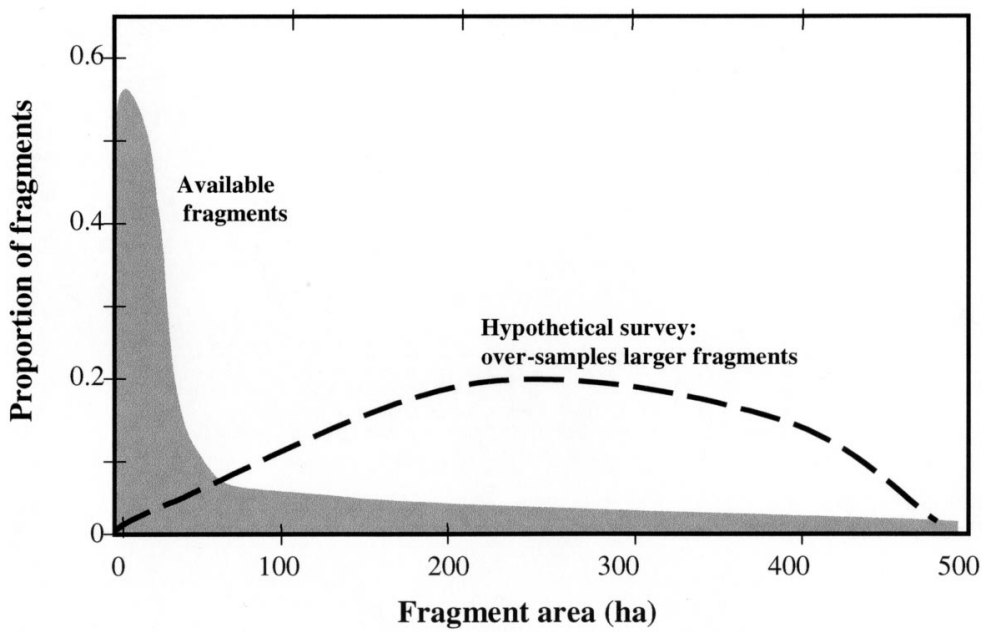

Figure 6 As is likely very common for most archipelagos, whether real or habitat islands such as illustrated here, most 'islands' tend to be very small. That is, the frequency distributions of island areas tend to be leptokurtic and strongly skewed to the right. On the other hand, most biological surveys tend to include a highly disproportionate number of larger islands (dashed line). Illustrated here is the frequency distribution of fragment sizes in the Hoodsport district of Olympic National Forest, WA, USA

Source: Lomolino and Perault, 2000; Perault and Lomolino, 2000 
inferences emerging from such studies may not be entirely accurate, unbiased reflections of the statistical population of the islands studied. Even the most rigorous and sophisticated studies of such biased subsets are unlikely to detect small island effects. Depending on the particular hypothesis or application, this may be deemed a trivial oversight. Then again, small island effects may be especially important for conservation biologist whose greatest challenges impinge on their ability to understand and maintain biological diversity among sets of relatively small and shrinking fragments (Figure 7).

For these and some other applications, a more complex mathematical model may be required; one that describes a sigmoidal relationship. A number of sigmoidal models have been used by ecologists and biogeographers. While these models lack the simplicity of the power or semi-log models, they may well provide a more accurate description of the species-area relationship. Recent studies have compared the efficacy of two related, sigmoidal models (the extreme value function - Williams, 1995; 1996; the logistic model - He and Legendre, 1996) to the more conventional models (power and semi-log; see also Scheiner et al., 2000). Although more extensive surveys and comparisons are needed, sigmoidal models seem to be superior, at least based on $r^{2}$ values. Then again, because they include an additional regression parameter (three versus just two in the power and semi-log models), higher explanatory power is not surprising.

Parameters in the sigmoidal models include estimates of: 1) the extent of the small island effect; 2) the generalized rate of increase in richness; and 3) the maximum species richness. Given an accurate estimate of the species pool, the latter parameter becomes a constant and sigmoidal models can be simplified to include just two regression parameters.

The hill-slope function, often used in physiological studies, may provide some distinct advantages over other models:

$$
S=S_{\max } /\left[1+\left(\text { Hill }_{\text {slope }} \wedge^{(\log (\text { A50/Area })}\right)\right]
$$

This model includes three parameters, all of which are readily interpretable in this application: $S_{\max }=$ the maximum richness, or asymptote; Hill ${ }_{\text {slope }}$ is a direct measure of the slope of the curve through the inflection point; and $A 50=$ the area yielding a richness equal to $50 \%$ of the maximum richness. All three of these parameters can be estimated using nonlinear, iterative regression method, or, if $S_{\max }$ is known, it can be

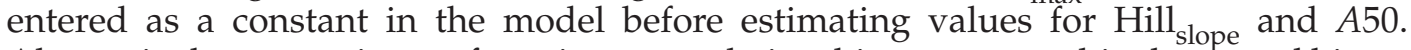
Alternatively, comparisons of species-area relationships among archipelagos and biotas derived from different species pools can be conducted by expressing $S$ as a proportion of the species pool $\left(S^{\prime}\right)$ and setting $S_{\max }$ to 1 . The hill-slope model (now $S^{\prime}=1 /[1+$ (Hill slope $\left(\log \left(A_{50} /\right.\right.$ Area $\left.\left.\left.)\right)\right]\right)$ can be used to compare the extent of the small island effect (a direct function of A50) and the relative slope of the species-area relationship

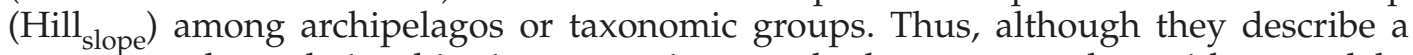
more complex relationship in comparison to both power and semi-log models, sigmoidal models such as the hill-slope formula may offer an alternative that is both statistically tractable (especially in the two parameter form) and biologically interpretable. 


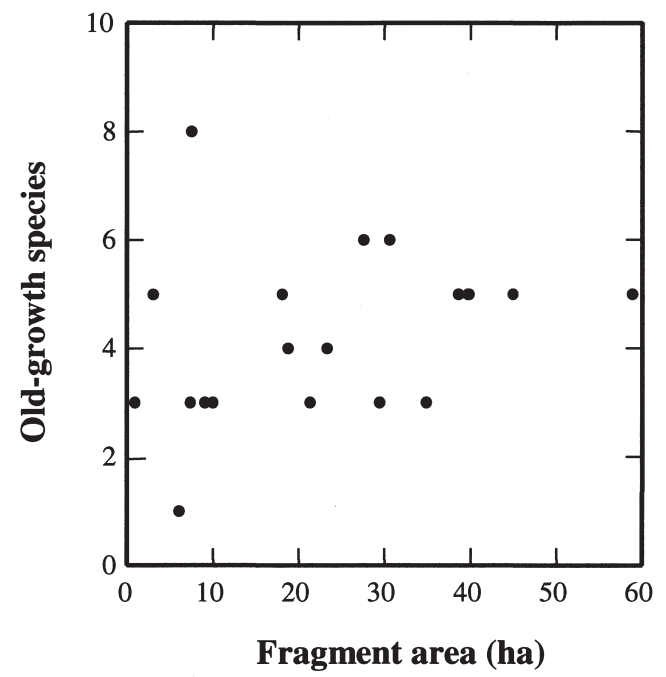

(a)

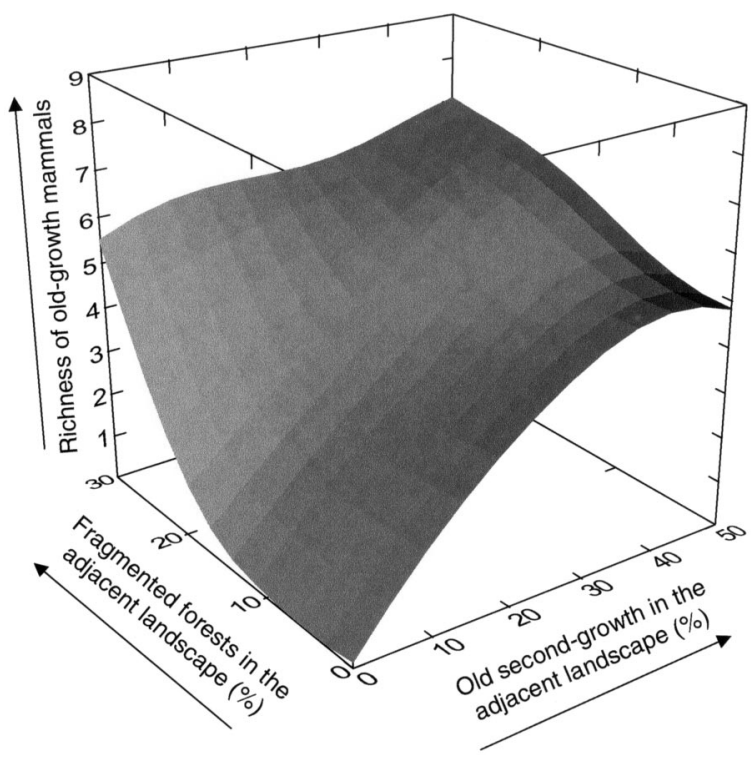

(b)

Figure 7 For the biota of archipelagos comprising relatively small islands, species richness may not be significantly correlated with area (a) but, instead, may be more strongly correlated with factors such as habitat quality of the island or fragment as well as characteristics of the adjacent landscape (nonvolant, forest mammals of fragmented, temperate rain forests of the Hoodsport district, Olympic National Forest, WA, USA

Source: Lomolino and Perault, 2000; Perault and Lomolino, 2000 


\section{Broad spatial and temporal scales}

When sampled across very broad spatial and temporal scales, species-area relationships may deviate in an even more fundamental way than discussed above. Over many generations, the biota of very large islands may continue to accumulate species, not by immigration, but by in situ speciation as well. In a recent re-evaluation of the equilibrium theory of island biogeography, Larry Heaney (2000) presented an insightful view of the role of in situ speciation, or phylogenesis. Drawing primarily on his studies of mammals of the Philippines, where some $85 \%$ of the nonvolant land mammals are endemic to this archipelago (see Heaney and Jacinto, 1998), Heaney cogently argued that phylogenesis cannot be modelled as just an additional form of immigration. More to the point, Heaney (2000) argues that the relationship between phylogenesis and island variables (area and isolation) is qualitative different from those for extinction and immigration (Figure 8). Therefore, species-area relationships should exhibit a secondary phase of increase when islands become large enough to provide both the spatial isolation and persistence times required for their populations to diverge to form distinct species (Figure 5, dashed line).

To be certain, inclusion of the potential importance of speciation significantly complicates what is typically viewed as an elegantly simple relationship. Yet this may be a much more accurate, and potentially more interesting and insightful, view of the forces influencing the diversity of isolated biotas. The conventional models (power or semi-log) provide little opportunity to explore the scale-dependent influences of local, stochastic variation and disturbance (most important on the very small islands), of immigration and extinction dynamics (on moderate to large islands), and in situ speciation (on the very large islands). In fact, an alternative and perhaps more fruitful approach to understanding the causal nature of the species-area relationship may be to abandon the search for 'canonical values' of regression slopes and instead compare the thresholds at which each of the above, scale-dependent processes have a dominant influence on the structure of insular communities (Figure 8; Lomolino, 2000b).

\section{A search for causation}

In 1972, Robert MacArthur - cofounder of the equilibrium theory - wrote that 'to do science is to look for repeated patterns in nature' (p. 1). However, as he demonstrated repeatedly in his illustrious, but tragically brief career, good science requires that we do much more than just draw curves and parameterize statistical models. Once a pattern is described, we then are challenged to test its generality, identify exceptional cases and, by using experimental and comparative approaches, propose and then rigorously evaluate causal explanations.

Given the long history of scientific studies of the species-area relationship, it should not be surprising that its putative, causal explanations are many. Johan Reinhold Forster, who described this relationship for islands in the eighteenth century, attributed it to the tendency for larger islands to have more resources and a greater diversity of habitats. Today, the list of alternative explanations for the species-area relationship is now quite long, and continues to grow, although many of the 'new' hypotheses include elements of those proposed long ago. According to these hypothesis, larger islands have 
higher richness because they include a greater diversity of habitats (Williams, 1964; Lack, 1947; 1970; Deshaye and Morisset, 1988), support higher population levels by providing more resources and energy (Preston, 1962; MacArthur and Wilson, 1963; 1967; Wright, 1983; Wylie and Currie, 1993), provide more refugia against a host of extinction forces including storms and other forms of disturbance (Rutzler, 1965; Jaenike, 1978; Sousa, 1979; McGuinness, 1984; Losos, 1998; Whittaker, 1998), can accommodate species with larger home ranges, intercept a greater diversity of

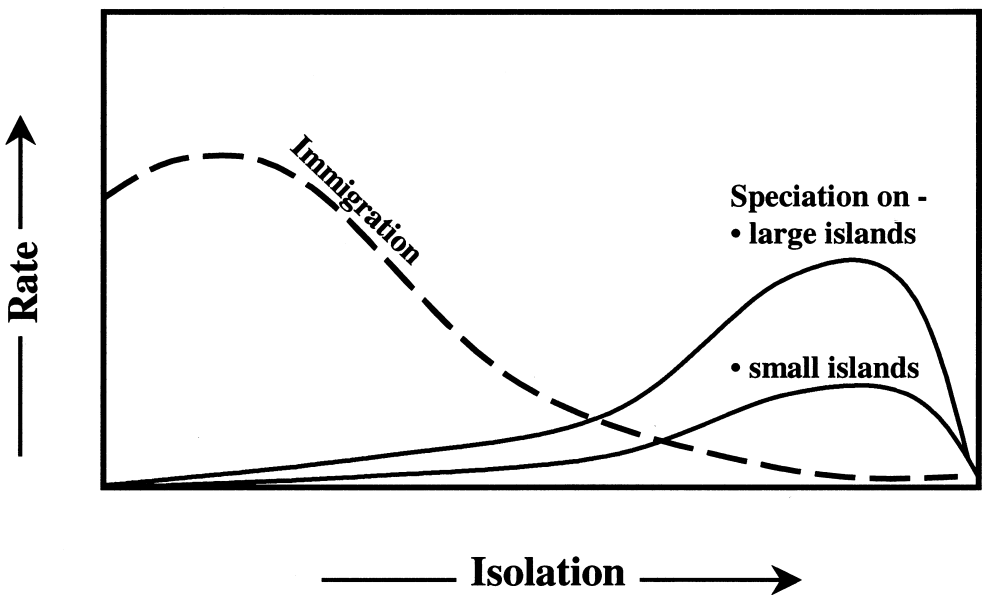

(a)

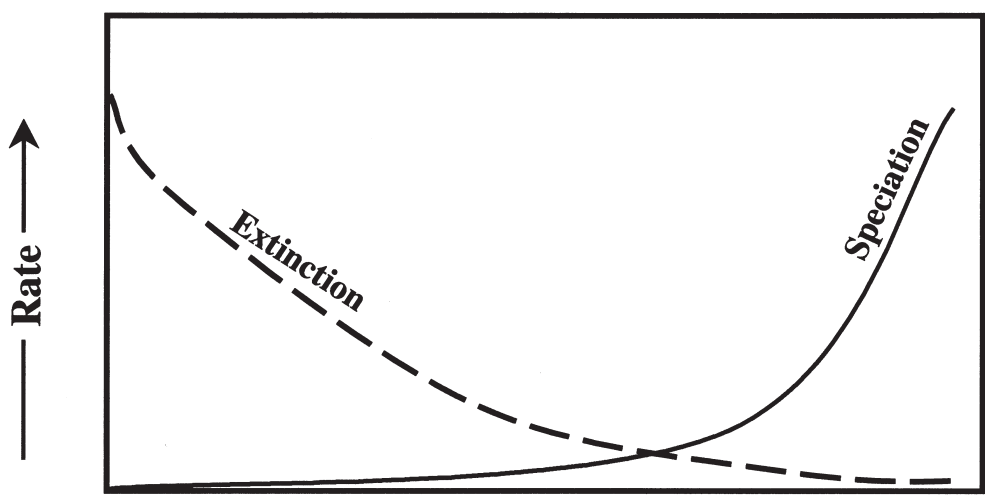

Island Area

(b)

Figure 8 The relationship between in situ speciation (phylogenesis, sensu Heaney, 2001) and island variables (isolation - (a) and area - (b)) is qualitatively different from those for immigration and extinction Source: Redrawn from Heaney, 2001 
immigrants (Simberloff, 1974; Gilpin and Diamond, 1976; Lomolino, 1990), receive greater sampling effort (Arrhenius, 1921; Gleason, 1922; Connor and McCoy, 1979; Coleman, 1981; Coleman et al., 1982; Hill et al., 1994), and provide the internal geographic isolation (large rivers, mountains and other barriers within islands) necessary for in situ speciation (Munroe, 1948; 1953; MacArthur and Wilson, 1967; Juvik and Austring, 1979; Adler, 1994; Heaney, 2001).

Obviously, these are not mutually exclusive hypotheses. Moreover, rather than resulting from any one, dominant biogeographic factor, very general patterns in nature such as the species-area relationship may derive from a combination of convergent forces. All these forces may ultimately express the influence of a more fundamental law of nature. Recent investigations on scaling laws in nature may provide a potentially unifying, conceptual framework for the science of the species-area relationship and a host of other, very general patterns in biogeography and ecology (Palmer and White, 1994; West et al., 1997; Enquist et al., 1998; see also Vilenkin and Chikatunov, 19981 NeyNifle and Mangel, 1999). The species-area relationship may be derived, quite simply in fact, from the equally general scaling pattern of body size in most life forms. For nearly all groups of species, frequency distributions of body size tend to be right-skewed and leptokurtic (Figure 9). Because resource requirements increase with body size, frequency distributions of resource and spatial requirements (i.e., area required to maintain viable populations of particular species) should also be right-skewed and

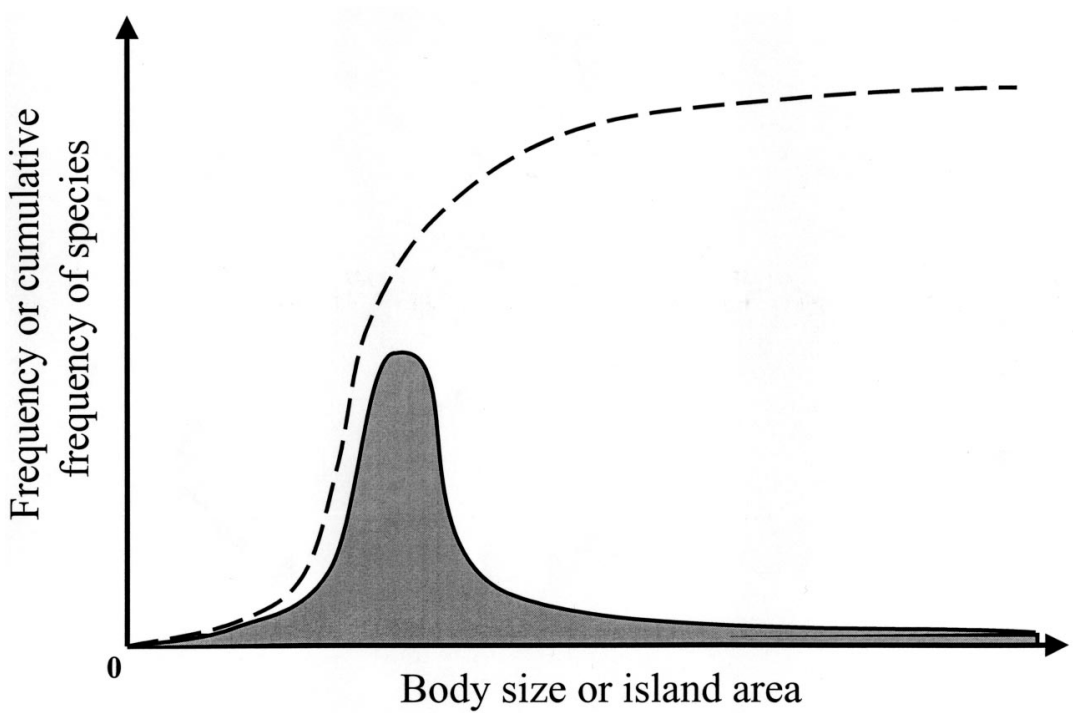

Figure 9 An alternative derivation of the species-area relationship based on fundamental scaling patterns of body size and resource requirements. Frequency distributions of body size and resource requirements (here the area required to maintain populations of particular species) in most groups of life forms tend to be right-skewed and leptokurtic. The cumulative number of species whose resource requirements are met by islands of varying size (dashed line) should, thus, increase as a sigmoidal function of area 
leptokurtic. Therefore, as we move along a gradient of increasing area, the cumulative number of species whose spatial requirements are satisfied on these islands increases (Figure 9). Note also that this accumulation curve, derived from very simple scaling laws, predicts that the species-area relationship should be sigmoidal.

\section{Applications in conservation biology}

Throughout the long history of biogeography, the species-area relationship has served as an important tool for understanding the geography of nature and, as such, it is likely to play an equally important role in designing effective strategies for conserving biological diversity. The species-area relationship was a fundamental tenet of the classic guidelines for designing nature reserves proposed by Diamond (1975) and Wilson and Willis (1975). Species-area curves are often used to assess the value of prospective or existing nature reserves, or to predict the loss in biological diversity associated with anthropogenic activities. Basically, this involves interpolating or extrapolating from theoretical or empirically derived species-area curves (typically, using the power model, assumed or measured $z$-values, and the predicted decline in area of native habitat; see Harris, 1984; Shafer, 1990; Bibby et al., 1992; McKinney, 1998).

Some newer and more creative approaches for predicting loss in biological diversity in response to anthropogenic loss of native habitats include McDonald and Brown's (1992) studies of montane mammals of the Great Basin (USA). Based on the global climate change scenario of doubling of $\mathrm{CO}_{2}$ concentrations, they were able to estimate the reduction of montane forests with warming of regional climates. Applying a species-area curve based on contemporary patterns of diversity, they were able to estimate how many species each montane forest would harbour after its area decreased following global warming (essentially by plugging the new, reduced area into the empirically derived formula for the power model; Figure 10). In addition to providing estimates of how many species would be lost from each forest, McDonald and Brown (1992) also predicted which species would be lost (basically, those that were less likely to occur on species-poor islands).

Brooks and his colleagues (Brooks et al., 1997; Brooks et al., 1999a; 1999a; 1999b) provide another creative application of species-area models in conservation biology. Consistent with general trends in species-area curves, they first assume that following fragmentation, $z$-values of the power model will increase from their mainland value (assumed to be 0.15 ) to 0.25 , which approximates the general trend for isolated communities. They then used the following formula to estimate the proportional loss of species that would occur once the fragmented communities have reached an equilibrium between their elevated extinction rates and reduced immigration rates:

$$
S_{\text {new }} / S_{\text {original }}=\left(\text { Area }_{\text {new }} / \text { Area }_{\text {original }}\right)^{z}
$$

This approach can be used to estimate not just the eventual number of species lost, but the rate of species loss, or the time-lags between initial fragmentation and complete relaxation. The results of these initial analyses are quite sobering. The extinction deficit (the time between fragmentation events and the associated loss in biological diversity) is in the range of decades to centuries (Brooks et al., 1999b). David Tilman and his colleagues (Tilman et al., 1994), although using a very different approach, offer similar 


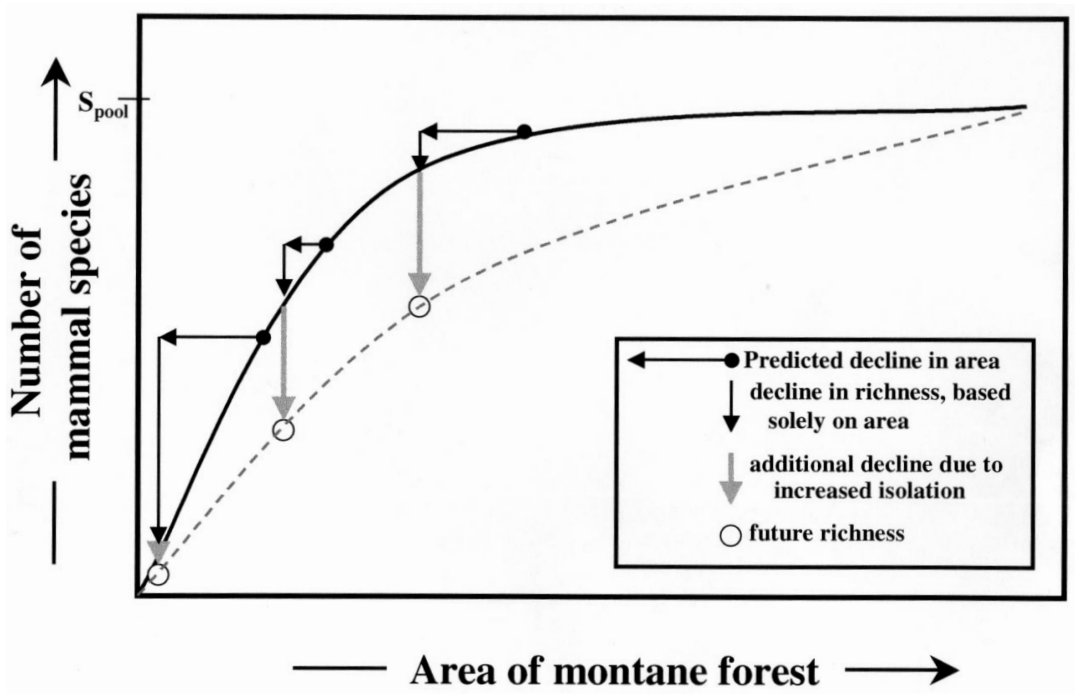

Figure 10 Species-area curves may be used to predict the potential loss in biodiversity resulting from anthropogenic reduction and fragmentation of native ecosystems. For example, McDonald and Brown (1992) applied global climate change scenarios to predict the decline in area of montane forest habitats of the Great Basin region (USA). They then applied the power model of the species-area relationship (using $c$ - and $z$-values derived from contemporary patterns) to predict the number of nonvolant mammals that should suffer extinction in each montane forest (summarized here for just three montane forest communities). These and similar applications of species-area curves may, however, underestimate future loss in biological diversity. Because fragmentation includes increasing isolation of remaining patches, species-area curves should not be constant but should decline (reduced $c$-value) and become flatter (increased $z$-value)

estimates for the duration of anthropogenic extinction debts; that is, the effects of recent and ongoing habitat loss and fragmentation may not be realized for centuries.

A note of caution is, however, necessary. Such applications, regardless of how creative and elegant, are only as good as the empirical data and theoretical constructs they were based on. Given the concerns expressed above regarding the true nature of the species-area relationship and, in particular, the explanatory power of the power model, such applications may be much more problematic than they first appear. Which values of $z$ and $c$ are we to use? Fragmentation includes increased isolation, as well as reduction in area of remaining fragments. Therefore, prospective species-area curves should differ significantly from those based on extant or historic distributions (c-values should decrease, while z-values should increase; dashed line in Figure 10). The power model may, in fact, be a poor predictor of species richness, especially for the very large or very small islands. Many of the refugia and remnants of once extensive native ecosystems may fall within the range of area where small island effects may be prominent. That is, the domain of conservation biology is rapidly becoming that of collections of relatively small ecosystems where correlations between species diversity 
and fragment area are often weak or nonsignificant (Figure 7). Here, other factors, such as local habitat conditions (within fragments), edge effects and characteristics of the intervening matrix, may influence native species diversity more strongly than island area (see Laurance and Bierregaard, 1997; Perault and Lomolino, 2000; Lomolino and Perault, 2000a; 2000b).

If they are to represent rigorous science, applications of the power model should include lists of underlying assumptions along with estimates of uncertainty associated with any predictions. On the other hand, where applications of relatively simple models prove tenuous, we may well have to resort to less glamorous, but possibly more cost-effective and reliable, empirical approaches. Given we have discovered only a small fraction of the earth's biological diversity, estimates of the relationship between area and what may well be an inestimable number of undescribed species seem specious. Strategically designed biological surveys, such as those conducted by the Smithsonian Institution's Rapid Assessment Program, represent invaluable tools for conserving biological diversity. Far from simple, effective biological surveys require use of advanced technological, theoretical and analytical procedures during all stages from initial design, to actual implementation of the survey and analysis and application of the results. Combined with continued advances in analytical methods and a solid conceptual framework, such surveys will provide the essential information for understanding and conserving biological diversity.

\section{Acknowledgements}

This research was supported, in part, by two grants from the National Science Foundations, USA (DEB-9322699, DEB-9707204). The current version of the manuscript has benefited from discussions with James H. Brown, Gregory A. Smith, Dov F. Sax, David R. Perault, Rob Channell and Morgan Ernest.

\section{References}

Adler, G.H. 1994: Avifaunal diversity and endemism on tropical Indian Ocean islands. Journal of Biogeography 21, 85-95.

Arrhenius, O. 1921: Species and area. Journal of Ecology 9, 95-99.

Bibby, C.J., Collar, N.J., Crosby, M.J., Heath, M.F., Imboden, C.H., Johnson, T.H., Long, A.J., Stattersfield, A.J. and Thirgood, S.J. 1992: Putting biodiversity on the map: priority areas for global conservation. Cambridge: International Council for Bird Preservation.

Blackburn, T.M. and Gaston, K.J. 1997: The relationship between geographic area and the latitudinal gradient in species richness in New World birds. Evolutionary Ecology 11, 195-201.

Brooks, T.M., Pimm, S.L. and Collar, N.J. 1997: Deforestation predicts the number of threatened birds in insular southeast Asia. Conservation Biology 11, 382-94.

Brooks, T.M., Pimm, S.L., Kapos, V. and Ravilious, C. 1999a: Threat from deforestation to montane and lowland birds and mammals in insular southeast Asia. Journal of Animal Ecology 68, 1-20.

Brooks, T.M., Pimm, S.L. and Oyugi, J.O. 1999b: Time lag between deforestation and bird extinction in tropical forest fragments. Conservation Biology 13, 1-11.

Brown, J.H. and Lomolino, M.V. 1989: On the nature of scientific revolutions: independent discovery of the equilibrium theory of island biogeography. Ecology 70, 1954-57.

- 1998: Biogeography. Sunderland, MA: Sinauer Associates.

Coleman, B.D. 1981: On random placement and 
species-area relations. Mathematical Biosciences 54, 191-215.

Coleman, B.D., Mares, M.A., Willig, M.R. and Hsieh, Y.-H. 1982: Randomness, area and species richness. Ecology 63, 1121-33.

Connor, E.F. and McCoy, E.D. 1979: The statistics and biology of the species-area relationship. American Naturalist 113, 791-833.

de Candolle, A.P. 1820: Essai élémentaire de géographie botanique. De l'imprimerie de F.G. Levrault.

Deshaye, J. and Morisset, P. 1988: Floristic richness, area, and habitat diversity in a hemiarctic archipelago. Journal of Biogeography $15,747-57$.

Diamond, J.M. 1975: Assembly of species communities. In Cody, M.L. and Diamond, J.L., editors, Ecology and evolution of communities, Cambridge: Belknap Press, 342-444.

Dony, J.G. 1963: The expectation of plant records from prescribed areas. Watsonia 5, 377-85.

Dunn, C.P. and Loehle, C. 1988: Species-area parameter estimation: testing the null model of lack of relationship. Journal of Biogeography 15, 721-28.

Enquist, B.J., Brown, J.H. and West, G.B. 1998: Allometric scaling of plant energetics and population density. Nature 395, 163-65.

Flather, C. 1996: Fitting species-accumulation functions and assessing regional land use impacts on avian diversity. Journal of Biogeography 23, 155-68.

Gilpin, M.E. and Diamond, J.M. 1976: Calculations of immigration and extinction curves from the species-area-distance relation. Proceedings of the National Academy of Sciences, USA 73, 4130-34.

Gleason, H.A. 1922: On the relationship between species and area. Ecology 3, 158-62.

Gould, S.J. 1979: An allometric interpretation of the species-area relationship: the meaning of the coefficient. American Naturalist 14, 335-43.

Haas, P.H. 1975: Some comments on the use of the species-area curve. American Naturalist 109, 371-72.

Hallam, A. 1983: Plate tectonics and evolution. In Bendall, D.S., editor, Evolution from molecules to men, Cambridge: Cambridge University Press, 367-86.

Harris, L.D. 1984: Island biogeography theory and the preservation of biotic diversity. Chicago, IL:
University of Chicago Press.

He, F. and Legendre, P. 1996: On species-area relations. American Naturalist 148, 719-38.

Heaney, L.R. 2000: Dynamic equilibrium: a longterm, large-scale perspective on the equilibrium model of island biogeography. Global Ecology and Biogeography 9, 59-74.

_ 2001: Small mammals diversity along elevational gradients in the Philippines: an assessment of patterns and hypotheses. Global Ecology and Biogeography 10, in press.

Heaney, L.R. and Jacinto, C.R. Jr. 1998: Vanishing treasures of the Philippine rain forest. Chicago, IL: The Field Museum.

Hill, J.L., Curran, P.J. and Foody, G.M. 1994: The effect of sampling on the species-area curve. Global Ecology and Biogeography Letters 4, 97-106.

Jaenike, J. 1978: Effect of island area on Drosophila population densities. Oecologia 36, 327-32.

Juvik, J.O. and Austring, A.P. 1979: The Hawaiian avifauna: biogeographic theory in evolutionary time. Journal of Biogeography 6, 205-24.

Lack, D. 1947: Darwin's finches. Cambridge: Cambridge University Press.

_ 1970. Island birds. Biotropica 2, 29-31.

Laurance, W.F. and Bierregaard, R.O. Jr. 1997: Tropical forest remnants: ecology, management and conservation of fragmented communities. Chicago, IL: Chicago University Press.

Lomolino, M.V. 1982: Species-area and species-distance relationships of terrestrial mammals in the Thousand Island region. Oecologia 54, 72-75.

__ 1984: Mammalian island biogeography: effects of area, isolation and vagility. Oecologia 61, 376-82.

— 1990: A test of the 'target area effect': the influence of island area on immigration rates of nonvolant mammals. Oikos 77, 297-300.

— 2000a: A species-based theory of insular zoogeography. Global Ecology and Biogeography Letters 9, 39-58.

— 2000b: Ecology's most general, yet protean pattern: the species-area relationship. Journal of Biogeography 27, 17-26.

_ 2001: Elevational gradients of species density: historical and prospective notes. Global Ecology and Biogeography 10, in press.

Lomolino, M.V. and Perault, D.R. 2000: Assembly and dis-assembley of mammal communities in a fragmented temperate rainforest. Ecology 81, 1517-32.

— 2001: Island biogeography and landscape ecology of mammals inhabiting fragmented, 
temperate rainforests. Global Ecology and Biogeography 10, in press.

Losos, J.B. 1998: Ecological and evolutionary determinants of the species-area relationship in Caribbean anoline lizards. In Grant, P.R., editor, Evolution on islands, New York: Oxford University Press, 210-24.

MacArthur, R.H. 1965: Patterns of species diversity. Biological Reviews 40, 510-33.

- 1969: Patterns of communities in the tropics. Biological Journal of the Linnean Society 1, $19-30$.

- 1972: Geographical ecology: patterns in the distribution of species. Princeton, NJ: Princeton University Press.

MacArthur, R.H. and Wilson, E.O. 1963: An equilibrium theory of insular zoogeography. Evolution 17, 373-87.

- 1967: The theory of island biogeography. Monographs in Population Biology 1. Princeton, NJ: Princeton University Press.

Martin, T.E. 1981: Species-area slopes and coefficients: a cautionary note on their interpretation. American Naturalist 118, 823-37.

McDonald, K.A. and Brown, J.H. 1992: Using montane mammals to model extinctions due to global change. Conservation Biology 6, 409-15.

McGuiness, K.A. 1984: Equations and explanations in the study of species-area curves. Biological Reviews 59, 423-40.

McKinney, M.L. 1998: On predicting biotic homogenization: species area patterns in marine biota. Global Ecology and Biogeography Letters 7, 297-301.

Munroe, E.G. 1948: The geographical distribution of butterflies in the West Indies. PhD dissertation, Cornell University.

- 1953: The size of island faunas. In Proceedings of the Seventh Pacific Science Congress (Pacific Scientific Association). Volume IV: zoology, Auckland: Whitcome \& Tombs, 52-53.

Ney-Nifle, M. and Mangel, M. 1999: Speciesarea curves based on geographic range and occupancy. Journal of Theoretical Biology 196, $327-42$.

Niering, W.A. 1963: Terrestrial ecology of Kapingamarangi Atoll, Caroline Islands. Ecological Monographs 33, 131-60.

Palmer, M.W. and White, P.S. 1994: Scale dependence and the species-area relationship. American Naturalist 144, 717-40.

Perault, D.R. and Lomolino, M.V. 2000: Corridors and mammal community structure across a fragmented, old-growth forest landscape. Ecological Monographs 70, 401-22.

Preston, F.W. 1962: The canonical distribution of commonness and rarity. Part I. Ecology 43, 185-215.

Rosenzweig, M.L. 1995: Species diversity in space and time. New York: Cambridge University Press.

Rutzler, K. 1965: Substratsstabilitat im marinen benthos als oekologischer Faktor, dargestellt am Beispieladriatischer Porifer. Internationale Revue der gesamten Hydrobiologie 50, 818-27.

Scheiner, S.M., Cox, S.B., Willig, M.R., Mittelbach, G.G., Osenberg, C.W. and Kaspari, M. 2000: Species diversity: scale effects and species-area curves. Evolutionary Ecology Research 2, 791-802.

Schoener, T.W. 1976: The species-area relationship within archipelagoes: models and evidence from island birds. Proceedings of the XVI International Ornithological Congress 6, 629-42.

Shafer, C.L. 1990: Nature reserves: island theory and conservation practice. Washington, DC: Smithsonian Institution Press.

Simberloff, D.S. 1974: Equilibrium theory of island biogeography and ecology. Annual Review of Ecology and Systematics 5, 161-82.

Sousa, W.P. 1984: Experimental investigations of disturbance and ecological succession in a rocky intertidal algal community. Ecological Monographs 49, 227-54.

Sukhanov, V.V. 2000: A lognormal speciesabundance structure and species-area relation. Journal of Biogeography, in press.

Tilman, D., May, R.M., Lehman, C.L. and Nowak, M.A. 1994. Habitat destruction and the extinction debt. Nature 371, 65-66.

Vilenkin, B.Y. and Chikatunov, V.I. 1998: Cooccurrence of species with various geographic ranges, and correlation between area size and number of species in geographical scale. Journal of Biogeography 25, 275-84.

Wallace, A.R. 1910: The world of life. London.

Watson, H.C. 1859: Cybele Britannica, or British plants and their geographical relations. London: Longman \& Company.

West, G.B., Brown, J.H. and Enquist, B.J. 1997: A general model for the origin of allometric scaling laws in biology. Science 176, 122-26.

Whitehead, D.R. and Jones, C.E. 1969: Small islands and the equilibrium theory of insular biogeography. Evolution 23, 171-79.

Whittaker, R.H. 1998: Island biogeography: ecology, 
evolution, and conservation. New York: Oxford University Press.

Wiens, H.J. 1962: Atoll environment and ecology. New Haven, CT: Yale University Press.

Williams, C.B. 1964: Patterns in the balance of nature and related problems in quantitative biology. New York: Academic Press.

Williams, M.R. 1995: An extreme-value function model of the species incidence and species-area relations. Ecology 76, 2607-17.

- 1996: Species-area curves: the need to include zeroes. Global Ecology and Biogeography Letters 5, 91-93.

Willig, M.R. and Lyons, S.K. 2000: A hemispheric assessment of scale dependence in latitudinal gradients of species richness. Ecology 80, 248-92.

Wilson, E.O. and Willis, E.O. 1975: Applied bio- geography. In Cody, M.L. and Diamond, J.M., editors, Ecology and evolution of communities, Cambridge: Belknap Press, 522-34.

Woodruffe, C.D. 1985: Vascular plant speciesarea relationships on Nui Atoll, Tuvalu, central Pacific: a reassessment of the small island effect. Australian Journal of Ecology 11, 21-31.

Wright, D.H. 1983: Species-energy theory: an extension of species-area theory. Oikos 41, 496-506.

Wright, S.J. 1981: Intra-archipelago vertebrate distributions: the slope of the species-area relation. American Naturalist 118, 726-48.

Wylie, J.L. and Currie, D.J. 1993: Species-energy theory and patterns of species richness. I. Patterns of bird, angiosperm, and mammal richness on islands. Biological Conservation 63, 137-44. 